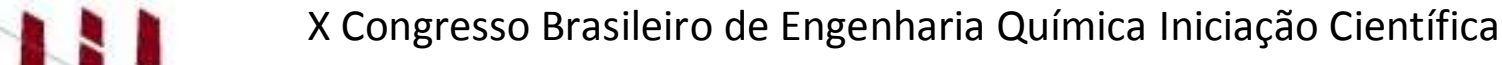 \\ "Influência da pesquisa em Engenharia Química no desenvolvimento tecnológico e industrial brasileiro" \\ Universidade Federal Rural do Rio de Janeiro Universidade Severino Sombra Vassouras - RJ-Brasil
}

\section{OBTENÇÃO DE COBALTO CONTIDO EM BATERIAS ÍON-LÍTIO ATRAVÉS DE LIXIVIAÇ̃̃̃O ÁCIDA}

\author{
M.L.SILVA ${ }^{1}$; C.M.MACHADO ${ }^{1}$;C.O.CALGARO ${ }^{2}$ e D.A.BERTUOL ${ }^{3}$ \\ ${ }^{1}$ Aluno do DEQ/UFSM ${ }^{2}$ Mestranda do DEQ/UFSM ${ }^{3}$ Professor do DEQ/UFSM \\ Departamento de Engenharia Química - Centro de Tecnologia - UFSM \\ Endereço - Av. Roraima 1000, Cidade Universitária, Camobi - Santa Maria, RS - CEP 97105-900 \\ email: mari_doria@hotmail.com
}

\begin{abstract}
RESUMO - Tendo em vista que a quantidade de lixo eletrônico tem aumentado consideravelmente devido aos avanços tecnológicos, faz-se necessário adotar medidas de reciclagem desses materiais. Dentre esses, destacam-se as baterias íon-lítio encontradas em celulares. Sendo assim, o presente estudo tem a finalidade de recuperar cobalto de baterias obsoletas, através de lixiviação ácida e eletroobtenção. O processo inicial adotado em todos os experimentos consistiu na abertura manual das baterias, a fim de separar a parte catódica, a qual é composta por uma folha de alumínio com materiais ativos de $\mathrm{LiCoO}_{2}$ aderidos. Em seguida, realizou-se uma raspagem na folha para retirar todo o material contido em sua superfície. Esse material removido foi, então, submetido à lixiviação ácida. Nessa etapa foi utilizado ácido sulfúrico $2 \mathrm{M}$ em diferentes relações sólido-líquido, sendo que em alguns casos acrescentou-se peróxido de hidrogênio. Na realização dos testes, foi variado o tempo e a concentração de peróxido de hidrogênio para analisar as condições ideais de lixiviação. As maiores concentrações de cobalto em solução foram obtidas quando o tempo de lixiviação foi de duas horas, sendo o melhor resultado encontrado quando se utilizou uma concentração de $20 \%$ de peróxido de hidrogênio.
\end{abstract}

Palavras chave: lixo eletrônico, metal, eletroobtenção.

\section{INTRODUÇÃO}

O tempo de vida de alguns equipamentos eletrônicos tem sido reduzido, tendo em vista o desenvolvimento de novas tecnologias. Deste modo, o descarte desses materiais, como as baterias íon-lítio de celulares, tem aumentado significativamente (KUMAR JHA, et.al., 2013). Essas baterias possuem grande importância devido características como alta densidade de energia, baixo peso, alta voltagem da célula e baixa taxa de autodescarga. De modo geral, a composição das baterias se divide em 5-20\% de cobalto, 5$7 \%$ de lítio, $5-10 \%$ de níquel, $15 \%$ de compostos orgânicos e $7 \%$ de plásticos. (KUMARI JHA, et.al., 2013)

Os constituintes de uma bateria íon-lítio são o cátodo, ânodo, eletrólito e o separador. O ânodo consiste em uma folha de cobre coberta por uma camada de carbono, enquanto $\mathrm{o}$ cátodo é feito de uma folha de alumínio 
coberta geralmente por uma camada de $\mathrm{LiCoO}_{2}$ (FERREIRA, et.al., 2009). O cátodo é um componente importante, pois determina a eficiência de corrente da célula (KUMAR JHA, et.al., 2013).

Segundo XU, et.al, (2008), as reações dos íons de lítio no cátodo e no ânodo são representadas pelas Equações 1 e 2.

$$
\begin{aligned}
& 6 \mathrm{C}+x \mathrm{Li}^{+}+x \mathrm{e}^{-} \leftrightarrow \mathrm{C}_{6} \mathrm{Li} \\
& \mathrm{LiCoO}_{2} \leftrightarrow \mathrm{Li}_{(1-x)} \mathrm{CoO}_{2}+x \mathrm{Li}+x \mathrm{e}^{-}
\end{aligned}
$$

O sentido direto da reação representa a reação de carga e o sentido inverso, a reação de descarga. A energia é armazenada nas baterias através do movimento dos íons de lítio do cátodo ao ânodo, ou seja, processo de carga. Quando esse movimento for no sentido inverso, ocorre o processo de descarga, como mostra a Equação 3 (XU, et.al., 2008).

$$
\mathrm{LiCoO}_{2+} 6 \mathrm{C} \leftrightarrow \mathrm{Li}_{(1-x)} \mathrm{CoO}_{2}+\mathrm{C}_{6} \mathrm{Li}_{x}
$$

O objetivo deste trabalho é recuperar cobalto de baterias íon-lítio em desuso, através de lixiviação ácida e posterior eletroobtenção.

\section{METODOLOGIA}

Foram utilizadas baterias íon lítio do modelo NOKIA - BL5B, as quais foram abertas manualmente, a fim de separar a parte catódica. A separação foi realizada com o objetivo de evidenciar a recuperação do cobalto, sem contaminações de outros metais provenientes das demais partes. Foi realizada uma raspagem para retirar o material aderido no cátodo, o qual possui o composto LiCoO2. Esse material foi submetido a uma lixiviação com ácido sulfúrico $2 \mathrm{M}$ e peróxido de hidrogênio. $\mathrm{O}$ ácido sulfúrico foi adicionado a uma relação sólido-líquido constante de 1:20, enquanto que o peróxido de hidrogênio foi acrescentado nas concentrações de 10,15 e 20 vol.\%. Os testes foram realizados a uma temperatura de $80^{\circ} \mathrm{C}$ nos tempos de 1 e 2 horas. Ao final da lixiviação, as soluções foram filtradas para serem utilizadas na etapa seguinte de eletroobtenção. A eletroobtenção foi realizada sob uma temperatura de $60^{\circ} \mathrm{C}$, densidade de corrente de 250 e $400 \mathrm{~A} / \mathrm{m}^{2}$, sob agitação e no tempo de 2 horas. Além disso, o $\mathrm{pH}$ foi mantido em um valor próximo de 4, através da utilização de uma solução anódica de sulfato de sódio 1M. Ao final dessa etapa, foi verificada a eficiência de corrente por meio da pesagem inicial e final do cátodo.

\section{RESULTADOS}

Inicialmente o pó da bateria utilizada foi submetido à difração de raio-X, a fim de confirmar a presença do composto desejado. Para isso, buscou-se como referência as análises de difração de raio-X encontradas na literatura para o composto em questão. Conforme mostra a Figura 1, foi detectada a presença de $\mathrm{LiCoO}_{2}$.

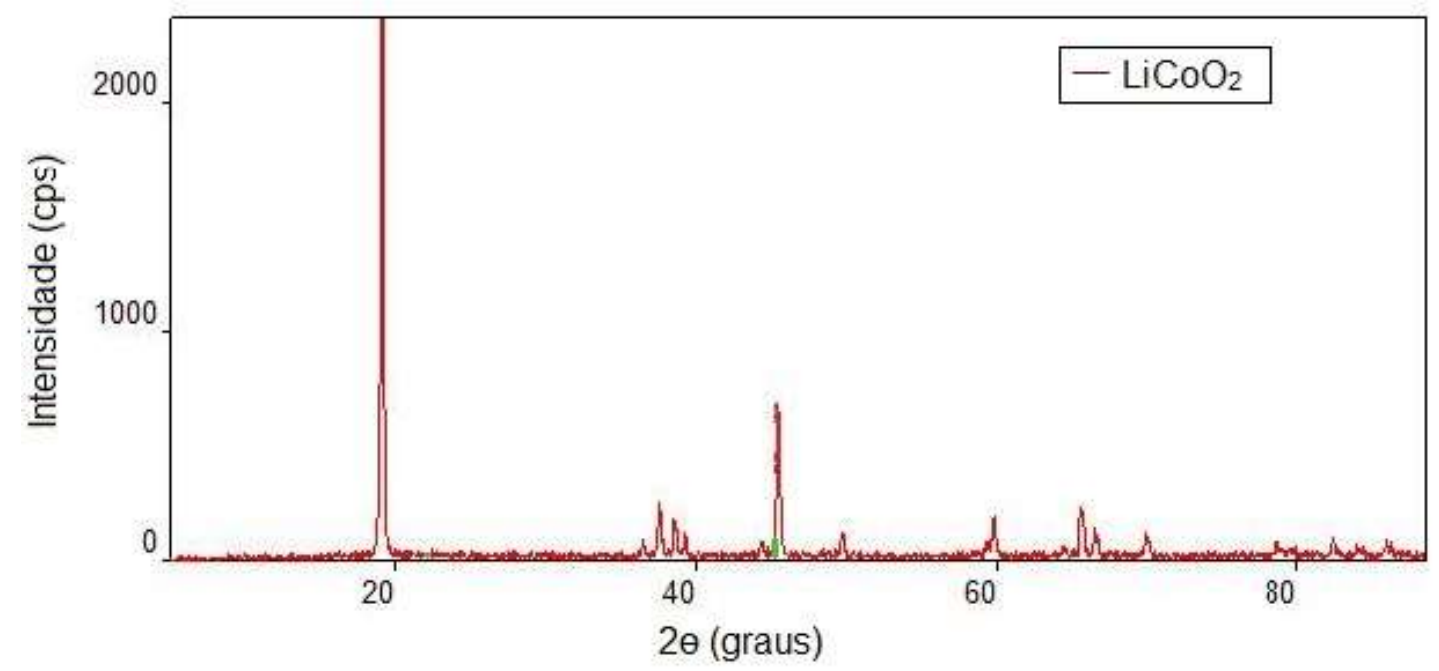

Figura 1 - Difração de raios-X do pó da bateria. 
A partir das análises das amostras após a lixiviação, por Espectroscopia de Absorção Atômica (AAS), foi possível determinar as concentrações de cobalto e lítio. Inicialmente, compararam-se os resultados obtidos para o tempo de lixiviação de uma hora, variando a concentração de peróxido de hidrogênio entre 10,15 e $20 \%$. Os resultados para as concentrações de lítio e cobalto são apresentados na Figura 2.

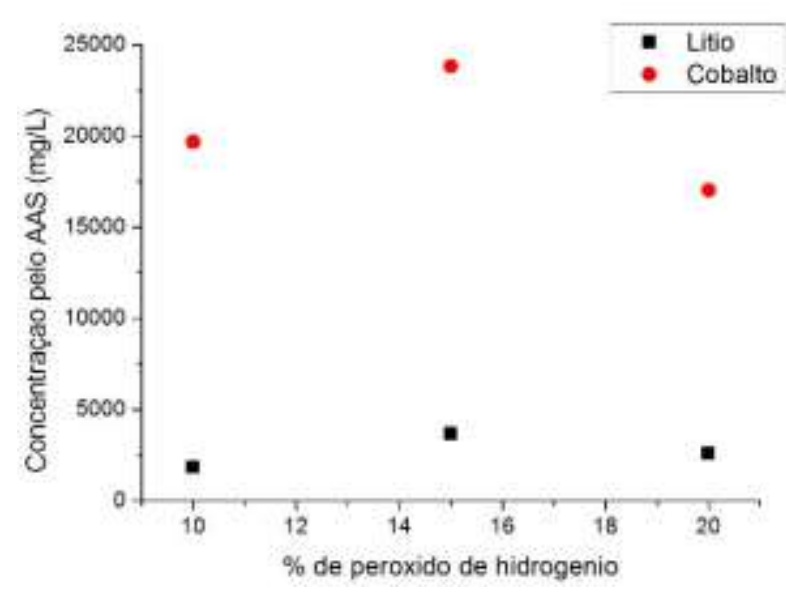

Figura 2 - Concentrações de cobalto e lítio para $1 \mathrm{~h}$ de reação.

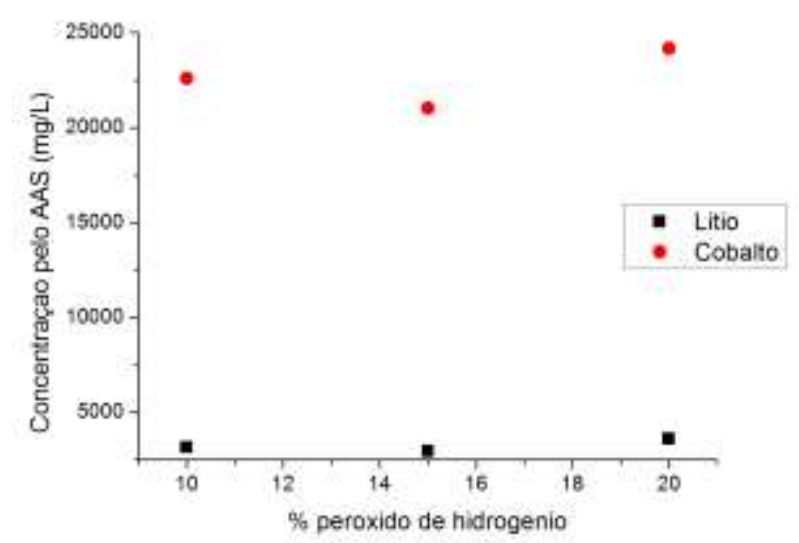

\section{Figura 3 - Concentrações de cobalto e lítio para $2 h$ de reação.}

A partir da Figura 2 é possível verificar que para o tempo de $1 \mathrm{~h}$ a maior concentração, tanto de cobalto quanto de lítio, foi obida quando se utilizou $15 \%$ de peróxido de hidrogênio.

A Figura 3 apresenta os resultados obtidos para o tempo de reação de duas horas. Conforme mostra essa figura, a maior concentração de cobalto e lítio corresponde aos experimentos em que se utilizou uma concentração de $20 \%$ de peróxido de hidrogênio.

O depósito obtido após realizar a eletroobtenção com a solução real, após a lixiviação, foi analisado através de difração de raio- $X$, a fim de verificar se ocorreu a recuperação de cobalto. A Figura 4 apresenta o resultado da análise, a qual indica a presença de cobalto no material. A comparação foi feita com o difratograma padrão para o composto em questão, e com os picos de difração do cobalto apresentados na literatura.

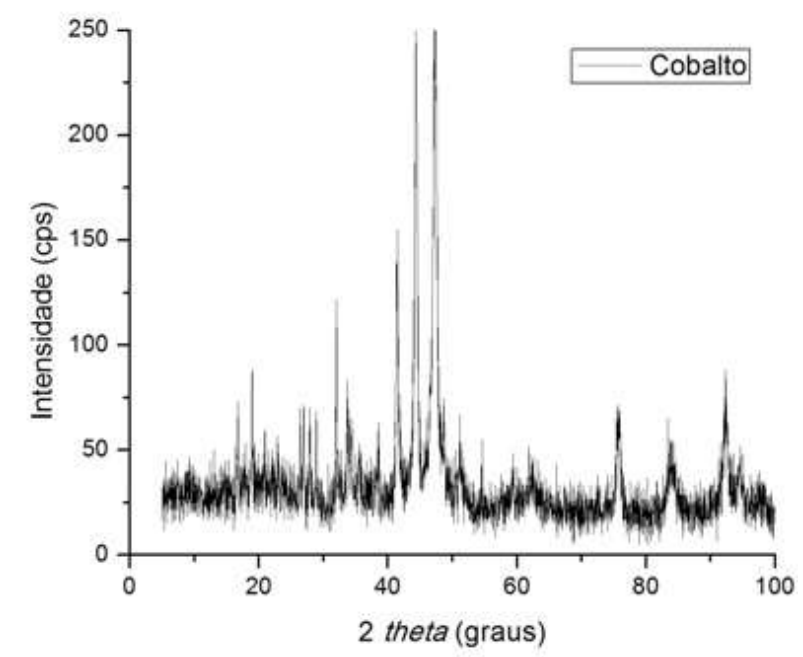

\section{Figura 4: Difratograma do depósito após a eletroobtenção.}

\section{CONCLUSÃO}

Com base nos dados obtidos a partir das análises por AAS, constatou-se que a condição de $20 \%$ de peróxido de hidrogênio e duas horas de lixiviação resultou na solução com maior concentração de cobalto. Ainda conforme os resultados, outra condição que apresentou concentração satisfatória do composto desejado foi a de uma hora de lixiviação e $15 \%$ de peróxido de hidrogênio. Uma vez que as concentrações nessas duas condições foram próximas, considerou-se a segunda condição apresentada como ideal. Isso porque a quantidade de material utilizada é menor, tornando o teste economicamente mais viável. Além disso, a análise de difração de raio-x realizada após a eletroobtenção indicou a presença de cobalto no material depositado, conforme o esperado. 


\section{REFERÊNCIAS}

FERREIRA, D. A. et.al. (2009). Hydrometallurgical separation of aluminium, cobalt, copper and lithium from spent Li-ion batteries. Journal of Power Sources 187, 238-246.

KUMAR JHA, M. K. et.al. (2013). Recovery of lithium and cobalt from waste lithium ion batteries of mobile phone. Waste Management 33, 1890-1897.
KUMARI JHA, A. et.al. (2013). Selective separation and recovery of cobalt from leach liquor of discarded Li-ion batteries using thiophosphinic extractant. Separation and Purification Technology 104, 160-166.

XU, J. et.al. (2008). A review of processes and technologies for the recycling of lithiumion secondary batteries. Journal of Power Sources 177, 512-527. 